Is not comparing distinction in different specialties like trying to compare apples with oranges? One way to minimise this impossible task would be for the available awards each year to be offered initially to each specialty roughly in proportion to their numerical strength; if there were not enough meritorious individuals in any specialty to justify all the awards the surplus could be redistributed that year to specialties with unsatisfied merit. This is not a new principle in the system; awards are at present regionalised and only transferred to another region if insufficient meritorious doctors can be identified in the region. I would be quite logical to extend this to interspecialty pooling and transfer.

Unless some revision is instituted we shall continue to be forced to try to compare apples with oranges, although in this instance, perhaps, a better metaphor would be plums with lemons, but never, we hope, breadfruit with sour grapes.

M Rosen M D VICKERS

Department of Anaesthesia,

University Hospital of Wales, Cardiff

\section{Hospital practitioner grade}

SIR,-To judge from Dr E B Lewis's statement to the General Medical Services Committee (25 February, p 523) I am afraid that the Hospital Consultants and Specialists Association's view on the hospital practitioner grade is being misrepresented by leaders of the Central Committee for Hospital Medical Services. We have three main objections to the grade as it is presently constituted, and the modification that has now been agreed with GMSC leaders does not correct them.

The first objection is that the grade is confined to principals in general practice. It means that many doctors with the same training and responsibility but who are not principals cannot qualify for this grade and must remain clinical or medical assistants posts that are lower paid and may be temporary. Doctors could be working side by side doing the same work yet paid different salaries. This discrimination is likely to affect women in particular, who might well wish to take up part-time hospital work of hospital practitioner grade responsibility after they have been registrars or even senior registrars in NHS hospitals but do not wish to take up general practice.

Secondly, the qualifications for this grade are too loosely defined, and sadly the new definition does not improve matters. Unless the necessary training and qualifications are clearly stated no clear standard of competence can be guaranteed.

Thirdly, it is quite wrong for the salary scale of this grade to overlap the consultant scale. Since the responsibility, experience, and training parallel those of registrars the sessional rate must be below that of the consultant, and until the salaries of senior hospital medical staff are raised to achieve this end the HCSA remains opposed to any appointments to this grade.

The hospital practitioner grade could be the grade of the future in the NHS. Consultants are beginning to realise that the present staffing structure in the hospital service must change soon, and with a sensible integration of doctors working outside hospitals-whether in general practice, the community health service, industrial medicine, or at home caring for their families-with those working entirely within hospitals a much more unified and viable service would be produced with greater job satisfaction for all.

\section{Alan B Shrank Deputy President Hospital Consultants and
Specialists Association} Ascot, Berks

**'The Secretary writes: "(1) The grade was proposed and negotiated specifically for general practitioner principals working in the NHS. This is why it was limited to five sessions. The extension of this principle to provide an all-purpose subconsultant career grade along the lines suggested by $\mathrm{Mr}$ Shrank raises important issues for hospital staffing. Meanwhile the Department is unwilling to enter into negotiations until the issues over the new consultant contract are settled.

“(2) Details of qualifications and experience for a particular grade are best left in the hands of the profession to be decided in the light of the requirements of the post to be filled. We do not agree with Mr Shrank's view that they should be determined by the Department of Health.

"(3) The fact that the consultant scale has been artificially depressed by the arbitrary imposition of discriminatory pay restraints should not be allowed to delay the introduction of a grade which is needed by the hospital service. It is unrealistic to expect general practitioners to carry out hospital sessions for less than they receive in general practice."- $\mathrm{ED}$, $B M \mathcal{~}$.

\section{Points from Letters}

\section{Coughing and huffing}

Dr H E Schablin (Stolberg, Rhineland) writes: "Is English the only language to have a word for forced expiration without prior glottal closure?" asks your contributor to "Words" (18 March, p 705). He suspects that the German "Hauch (breath, in the sense of exhalation)" may be related to huff. However, Hauch is the result of forced exhalation and thus is not the same as breath (Atem). Surely we cough with the glottis closed, we blow with the glottis open and the lips nearly closed, and we huff with glottis and lips open (although according to the Concise Oxford Dictionary "to huff" and "to blow" appear to be synonyms). The German anatomical equivalents of these three verbs are husten, blasen, and hauchen....

Dr P SkrabaneK (Dublin) writes: Your "Words" correspondent (18 March, p 705) errs in stating that the Slavs are "huffers." They are all "coughers." For example, Russian kashel (a cough), Czech kašel (a cough), or Bulgarian kashlitsa (a cough). In fact, even the Germanic words husten and hoste are reflexes of a Proto-Indo-European verbal root for "cough" that had an initial k-. The change of $k$ - into $h$ - is part of the famous First Germanic Sound Shift (Grimm's law). ...

\section{Who discovered the circulation of the} blood?

Dr S AL-DaBbagh (Oxford) writes: To the question "Who discovered the circulation of the blood ?" asked and partially answered by
Mr E G Tomich (1 April, p 852), may I add the fact that Ibn al-Nafis (AD1210-88), an Arab Muslim physician from Damascus, later Chief Physician of Egypt, ${ }^{1}$ discovered, by theoretical reasoning, the lesser or pulmonary circulation of the blood 300 years before William Harvey discovered the greater circulation by experiment." Ibn al-Nafis, in his commentary on the anatomy of Ibn Sina, in striking contrast to Ibn Sina and Galen, described the lesser or pulmonary circulation almost correctly nearly three centuries before the European discoverers of it, Michael Servetus and Realdo Colombo....

'Arabic Concise Encyclopaedia, p 59. Cairo, 1965.
2 The Legacy of Islam, ed J Schacht and C E Bosworth,
2nd edn, p 4. London, Oxford University Press,
1974.

\section{Postcoital test}

Dr J Slome (London W1) writes: May I congratulate Mr G T Kovacs and others (1 April, p 818) on their study, which places the value of the postcoital test (PCT) in true perspective? Nearly 10 years of experience with artificial insemination (donor) (AID) led me to the same conclusion some time ago-that the number of sperms present in cervical mucus following AID (and therefore normal intercourse) bore no relationship to whether or not the patient became pregnant. It occurred to me that if there are many sperms in the cervical mucus $\mathrm{X}$ hours after intercourse (or artificial insemination), then one could postulate that there is something preventing the sperms from swimming away from the cervical canal into the uterus-that is, that finding many sperms in the PCT was a bad sign and not a good sign as is traditionally taught. I suggest that the only value of a PCT is that it can show if agglutination of sperms has occurred since being placed in the cervical mucus. If the problem is one of male infertility the PCT is not a substitute for a proper semen analysis and it should never be used as a substitute for analysis....

\section{Posts in the Middle East}

Dr M DODDRIDGE (Riyadh, Saudi Arabia) writes: I would like to add another point to Dr P E Conen's letter (11 March, p 652). When a contract ends or is ended the employer can issue a "no objection" letter enabling the employee to seek employment with another employer-that is, change his sponsorship without the three-year rule applying-but this is entirely at the discretion of the employer. This was originally introduced to prevent employees from changing employment for higher salaries in an effort to curb the wages spiral and is applied to all non-Saudi workers who have to be sponsored before they can obtain a work permit to work in Saudi Arabia.

\section{Errant suffix}

Dr J M Henderson (Hoylake, Wirral, Merseyside) writes: I seem to recall being taught, many years ago, that Lauder Brunton introduced amyl nitrite for the relief of angina pectoris-not amyl nitrate as stated in your leading article on Harvey (1 April, p 803). The reason for the errant suffix may be either a printing error or the fact that amyl nitrite has now largely been replaced by glyceryl trinitrate. 